\title{
Soil phosphorus determines the distinct assembly strategies for abundant and rare bacterial communities during successional reforestation
}

\author{
Ziheng Peng, Zhifeng Wang, Yu Liu, Tongyao Yang, Weimin Chen, Gehong Wei", Shuo Jiao* \\ State Key Laboratory of Crop Stress Biology in Arid Areas, Shaanxi Key Laboratory of Agricultural and Environmental Microbiology, \\ College of Life Sciences, Northwest A\&F University, Yangling 712100, China
}

H I G H L I G H T S

- Soil phosphorus shaped both abundant and rare bacterial communities.

- Both abundant and rare bacteria exhibited different assembly strategies with successional reforestation.

- Deterministic processes increased with succession reforestation.

\section{ARTICLE INFO}

Article history:

Received April 25, 2021

Revised May 31, 2021

Accepted June 3, 2021

Keywords:

Rare bacteria

Reforestation

Soil profiles

Community assembly

Soil phosphorus

Semi-arid
GRAPHICAL ABSTRACT

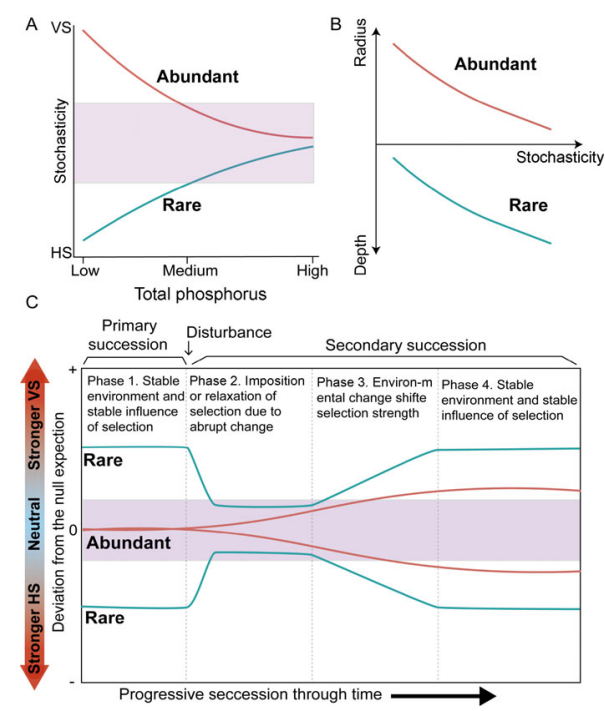

A B S T R A C T

Uncovering the mechanisms underlying the diversity patterns of abundant and rare species is crucial for terrestrial biodiversity maintenance. However, the response of abundant and rare community assembly to ecological succession has not been explored, particularly considering soil profiles. Here 300 soil samples were collected from reforestation ecosystems from depths of up to $300 \mathrm{~cm}$ and horizontal distances of $30-90 \mathrm{~cm}$ from a tree. We revealed that soil phosphorus not only affected alpha diversity and community structure, but also mediated the balance of stochastic and deterministic processes for abundant and rare sub-communities, which exhibited contrasting assembly strategies. The abundant sub-community changed from variable selection to stochasticity with the increase of phosphorus, while the rare sub-community shifted from homogeneous selection to stochasticity. Dispersal limitation was the main assembly process in the abundant sub-community, while the rare sub-community was governed primarily by homogeneous selection. Moreover, the relative influence of deterministic processes increased with succession for both sub-communities. At the scale of a single tree, stochastic processes increased with soil depth in rare sub-community, while deterministic processes increased with the radius from a single tree in the abundant subcommunity. Overall, our results highlight the importance of the soil phosphorus-driven assembly process in understanding the re-assembly and maintenance of soil bacterial diversity.

(c) Higher Education Press 2021

\footnotetext{
* Corresponding authors

E-mail address: weigehong@nwsuaf.edu.cn (G. Wei); shuojiao@nwsuaf.edu.cn (S. Jiao)
} 


\section{Introduction}

Ecological succession, which describes how biological communities re-assemble and shift over time following natural or anthropogenic disturbance, has always been an important theme for ecological research (Fukami, 2015; Chang and Turner, 2019). Ecological succession after disturbance leads to significant changes in the structure of the natural community of the ecosystem (Prach and Walker, 2011; Thom and Seidl, 2016). At the same time, communities of single-celled microorganisms are also affected by ecological succession (Fierer et al., 2010; Morriën et al., 2017), thereby influencing ecosystem functions (Chiquoine et al., 2016). Recent successional studies have provided insight into the community assembly mechanisms and species coexistence of macroorganisms and microorganisms (HilleRisLambers et al., 2012; Dini-Andreote et al., 2015; Chang and HilleRisLambers, 2016). Typically, communities usually contain a small number of high-abundance species (abundant taxa) and a large number of low-abundance species (rare taxa) (Jousset et al., 2017). With the rapid development of high-throughput sequencing, recent studies have shown that rare taxa play a key role in mediating the stability and function of ecosystems (Lynch and Neufeld, 2015). However, it has not yet been studied on how the abundant and rare bacteria change with the reforestation succession.

Our understanding of microbial ecology has also developed from descriptions of simple patterns in which communities are classified based on the identities and sizes of local species pools to the mechanisms underlying community assembly, which seeks to reveal the processes determining the generation and maintenance of local species pools (Ovaskainen et al., 2017). Usually, community assembly processes are divided into deterministic and stochastic processes (Stegen et al., 2012; Stegen et al., 2013). Deterministic processes involve ecological selection imposed by environmental filtering and biological interactions (Fargione et al., 2003). Stochastic processes, in contrast, involve random birth and death, random dispersal, and ecological drift (Chave, 2004). A null model analysis was used to evaluate assembly processes of microbial community based phylogenetic and taxonomic $\beta$ diversity metrics ( $\beta N T I$ and Bray-Curtis-based Raup-Crick, RCbray) (Stegen et al., 2013), which could well quantify the contributions of each assembly process. Assembly mechanisms of the abundant and rare bacteria communities have been investigated in a wide range of habitats, including agricultural soil (Jiao and Lu, 2020; Hou et al., 2020), oilcontaminated soil (Jiao et al., 2017a), temperate deserts (Wang et al., 2021), coastal wetlands (Gao et al., 2020), marine (Wu et al., 2017; Mo et al., 2018), and inland freshwater (Liu et al., 2015) habitats. In agricultural soil, the deterministic process was the main assembly processes for both the abundant and rare sub-communities (Jiao and Lu, 2020), but a contrasting result was found in another study in rice fields that communities of rare bacterial taxa were driven mainly by stochastic process (Hou et al., 2020). This may be due to the difference in sampling time. In coastal wetland soils, rare species were more phylogenetically clustered and primarily governed by deterministic process, while abundant species were more over-dispersed and dominated by dispersal limitation (Gao et al., 2020). However, the opposite trends were observed in oil-contaminated soil (Jiao et al., 2017a). These results indicate that the community assembly of the abundant and rare bacteria may vary with ecosystem type.

Ecosystems undergoing succession provide an ideal system for exploring changes in the community assembly of the abundant and rare bacteria along complex environmental gradients; succession provides a series of soils of different ages with varying abiotic and biotic characteristics (Bardgett, 2005). Recent studies have indicated that soil $\mathrm{pH}$ and soil organic matter mediate the balance between stochastic and deterministic assembly of bacteria in successional systems (Dini-Andreote et al., 2015; Tripathi et al., 2018). Shifts in the strength of environmental selection and dispersal rates due to succession influence the balance of deterministic and stochastic processes underlying microbial community assembly across time and space and from one system to another (Dini-Andreote et al., 2015; Evans et al., 2017; Tripathi et al., 2018). Previous studies have shown that the relative influence of the deterministic process gradually increases as the succession progresses (Dini-Andreote et al., 2015). This suggests that disturbance could promote a time-dependent shift in the stochastic and deterministic balance (Ferrenberg et al., 2013; Zhou et al., 2014; Dini-Andreote et al., 2015). There are few studies on how the assembly processes of the abundant and rare bacteria communities change with the progression of succession.

A growing number of researches focused on those microbes living in the subsurface soil as their key roles in nutrient cycling and soil formation (Eilers et al., 2012; Rime et al., 2015; Jiao et al., 2018; Chen et al., 2019a). Meanwhile, the deeper layers of soil also contain about $35 \%$ of microbial biomass in forest soils and are home to various microorganisms (Hartmann et al., 2009; Eilers et al., 2012). Moreover, microorganisms that inhabit deep soil play essential roles in soil formation, groundwater quality maintenance, and nutrient cycling (Fierer et al., 2003; Hartmann et al., 2009; Eilers et al., 2012; Jiao et al., 2018). During ecological succession, the effects of plants on soil physicochemical properties and microbial communities are not limited to the surface soil layer but are also present in deep soil via the root system (Pereira et al., 2017). However, the variations in the assembly processes of the abundant and rare microbial communities across vertical and horizontal soil profiles from around a tree at a fine-scale during ecological succession are not well understood.

Our previous study (Jiao et al., 2018) investigated how the soil microbiome responds to the restoration process and their contribution to soil nutrient cycling in soil profiles. We found that bacterial and archaeal beta-diversity drive multi-nutrient 
cycling in deep and superficial layers, respectively. In this study, the spatiotemporal patterns and assembly processes of the abundant and rare bacterial communities were investigated through vertical and horizontal soil profiles in an ecosystem undergoing ecological succession. A well-established chronosequence of reforestation sites on a former farm, representing over 30 years of nature restoration, was selected as an ecological succession model (Fig. 1). In general, the abundant and rare taxa had distinct life strategies, and the rare species typically exhibited weaker environmental adaptability with a narrow ecological niche and were more susceptible to environmental selection (Lynch and Neufeld, 2015). We hypothesized that (i) abundant and rare bacteria are governed by stochastic and deterministic assembly processes, respectively, and the influence of deterministic processes on the abundant and rare community assembly increases as succession progresses; (ii) the abundant and rare sub-communities exhibit distinct community assembly pattern around vertical and horizontal soil profiles at a single tree; and (iii) different environmental factors regulate the assembly processes of the abundant and rare sub-communities. This study will provide a novel insight into the assembly processes of the abundant and rare bacteria in successional ecosystems and promote our understanding of the generation and maintenance of the abundant and rare species during ecological succession.

\section{Methods}

\subsection{Field area and experimental design}

The experiment was conducted in the south of the Loess Plateau in China. The Plateau has a continental monsoon climate with a mean temperature of $12.7^{\circ} \mathrm{C}$ and an average rainfall of $580 \mathrm{~mm}$ per year (Jiao et al., 2018). The experimental sites were in the proximity of Yehe Mountain and comprise part of a reserve forest representing over 30 years of nature restoration (as the land was previously farmed). Reforested soils were separated into three stand ages: 10, 20, and 30 years. Black locust (Robinia pseudoacacia) was the dominant tree species. The farmland planting wheat and maize in rotation near the reforestation sites was also selected for the study.

Sampling points were selected from three forest-agespecific sites: 10, 20, and 30 years in the reforested land. Three plots with an area of $10 \times 10 \mathrm{~m}^{2}$ each were randomly established at each stage of succession as three replicates, and the adjacent plots were separated by $80-100 \mathrm{~m}$. In each plot, we choose a tree as the center for sampling, and the distance between this tree and other trees is at least $2 \mathrm{~m}$. Three soil samples were collected at evenly distributed radii of 30,60 , and $90 \mathrm{~cm}$ from the trunk, and ten soil samples were collected from a $0-300 \mathrm{~cm}$ vertical profile, corresponding to depths (cm) of 10, 20,40,60, 80, 100,150, 200, 250, 300. We divided these ten depths into three soil layers: top $(10,20$, and
$40 \mathrm{~cm})$, middle $(60,80$, and $100 \mathrm{~cm})$, deep $(150,200,250$, and $300 \mathrm{~cm}$ ). For each center tree, a total of 30 samples were collected. In the farmland, three soil sites were chosen that were $500 \mathrm{~m}$ apart from each other, and ten soil samples were collected from a $0-300 \mathrm{~cm}$ vertical profile at each site, similar to reforested land. Each soil composite sample was composed of five soil cores. Five soil cores were evenly distributed on the circumference of a circle at each radial distance around the tree. In total, 300 samples ( 3 replications $\times 10$ depths for the farmland and 3 replications $\times 10$ depths $\times 3$ radii $\times 3$ ages for the reforested soils) were obtained (Fig. 1). To avoid the mixing of the different depths, we collected the soil samples of one layer at a time from the top to the deep layers. Soils were transported to the laboratory immediately to remove plant roots, litter, stones, and debris, and all samples were divided into two subsamples. One set of subsamples was stored in sterile plastic bags at $-80^{\circ} \mathrm{C}$ for DNA analysis, and the other set was used for physicochemical analysis.

\subsection{Soil physicochemical characterization}

The soil subsamples destined for physicochemical analysis were sieved to $<2 \mathrm{~mm}$. The soil $\mathrm{pH}$, and the organic matter $(\mathrm{OM})$, nitrate $\left(\mathrm{NO}_{3}{ }^{-} \mathrm{N}\right)$, available phosphorus (AP), available potassium (AK) and total phosphorus (TP) contents of the samples were quantified as described by Bao (Bao, 2000).

\subsection{DNA extraction, sequencing, and processing}

High-throughput analysis of bacterial DNA has been well described previously (Jiao et al., 2018; Chen et al., 2019b). Briefly, genomic DNA was extracted from $0.5 \mathrm{~g}$ of the soil samples using the MP FastDNA spin kit for soil (MP Biomedicals, Solon, OH, USA) according to the manufacturer's instructions. The bacterial 16S rRNA genes were amplified using the primer pair 515F/907R. The purified PCR amplicon products were sequenced using the Illumina MiSeq (300 bp paired-end reads) platform (Illumina Inc., San Diego, USA). The acquired sequences were filtered for quality according to the methods of Caporaso et al. (2011), and chimeric sequences were removed using the UCHIME algorithm with the USEARCH tool (Edgar et al., 2011). Operational taxonomic units (OTUs) were constructed at a 97\% identity level using UPARSE (Edgar et al., 2011). OTUs with less than two sequences were removed, and the representative OTU sequences were classified using the SILVA database release 128 for bacteria.

\subsection{Statistical analyses}

A null model analysis was conducted (Stegen et al., 2013) to divide community pairs into drivers of deterministic and stochastic processes. The variation involved in phylogenetic diversity and taxonomic diversity was measured through null model-based phylogenetic and taxonomic beta-diversity 
metrics ( $\beta$-nearest taxon index [ $\beta \mathrm{NTI}]$ and Bray-Curtis-based Raup-Crick $\left.\left[\mathrm{RC}_{\text {Bray }}\right]\right)$. A conspicuous deviation $(|\beta N T I|>2)$ demonstrates the dominance of selection processes. To be specific, $\beta \mathrm{NTI}<-2$ indicates drastically less phylogenetic turnover than expected (representing homogeneous selection), and $\beta N T 1>2$ represents more turnover than expected (representing variable selection). Furthermore, when $|\beta N T \||<$ $2, \mathrm{RC}_{\mathrm{Bray}}$ was utilized to separate further the pairwise comparisons that were not designated a selection process. For instance, if $|\beta N T| \mid<2$ and $\mathrm{RC}_{\text {Bray }}<-0.95$, the community turnover was likely due to homogenizing dispersal. When $|\beta \mathrm{NTT}|<2$ and $\mathrm{RC}_{\mathrm{Bray}}>0.95$, dispersal limitation was assigned. Lastly, the fractions of pairwise comparisons with $|\beta N T| \mid<2$ and $\left|R C_{\text {Bray }}\right|<0.95$ were associated with the impact of "undominated" gathering, which mostly comprises poor selection, weak dispersal, diversification, and/or drift (Zhou and Ning, 2017; Tripathi et al., 2018).

Differences in alpha diversity among successional stages, soil profiles, and radii from the tree trunks were assessed using linear mixed-effects models (LMMs) with the "Ime4" (Bates et al., 2015) and "ImerTest" packages (Kuznetsova et al., 2017) in R v3.6.1. Samples from the same tree (reforest soils) or the same cores (farmland) were considered random effects. The main environmental predictors for the alpha diversity of the abundant and rare communities were identified using a random forest (RF) analysis for classification. The significance of each predictor on the response variables was assessed with the "rfPermute" package (Archer, 2016). Mantel and partial Mantel tests were used in the "ecodist" package (Goslee and Urban, 2007) in R to assess the relationship between phylogenetic turnover and environmental variables. To evaluate the phylogenetic community assembly, the SES. MNTD was calculated using the null model "taxa.labels" (999 randomization) with the "ses.mntd" function in the "picante" package (Kembel et al., 2010). Lower values of SES.MNTD show phylogenetic clustering (i.e., co-occurring OTUs are more closely related than expected by chance). The variation in community assembly processes along the gradients of the derived environmental variables (soil TP for the abundant and the rare sub-communities) was assessed using regression analysis to compare the $\beta \mathrm{NTI}$ values with the Euclidean distance matrices of soil TP. To assess the community assembly of the abundant and rare communities over the two-dimensional vertical and horizontal soil profiles, spatial distributions of stochastic processes were mapped using ordinary kriging interpolation in the "gstat" package (Pebesma and Heuvelink, 2016) in R. Generalized dissimilarity models (GDMs), in R using the "gdm" package (Glassman et al., 2017), are examined to quantify nonlinear relationships between abundant and rare bacterial composition and environmental factors. Variables are standardized, so they can be directly compared with one another, and GDM is highly robust to multicollinearity among predictors. Compositional dissimilarity of the abundant and rare communities was characterized by including abundance with the Bray-Curtis metric using the "vegan" package in R (Oksanen et al., 2013).

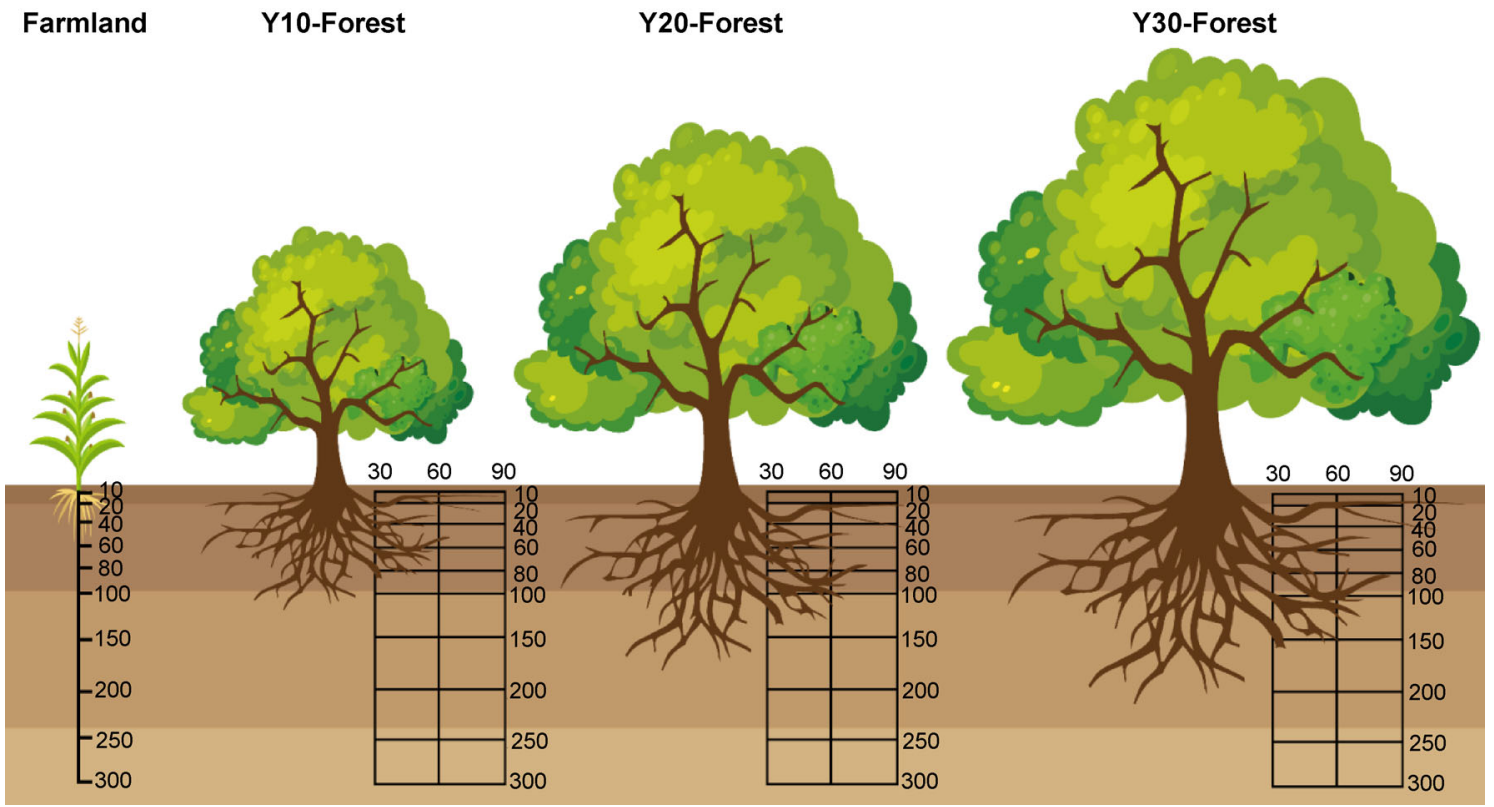

Fig. 1 Experimental design. Sampling points were conducted in four successional stages: Farmland, Y10-Forest, Y20-Forest, Y30-Forest. In farmland, soil samples were collected from a 0-300 cm vertical profile, corresponding to depths (cm) of 0-10, 10-20, 20-40, 40-60, 60-80, 80-100, 100-150, 150-200, 200-250 and 250-300. In reforestation, soil samples were taken at evenly distributed radii of 30, 60, and 90 cm distances to the trunk and from a 0-300 cm vertical profile. In sum, 300 samples $=3$ replications $\times 10$ depths (farm land) +3 replications $\times 3$ radius $\times 10$ depths $\times 3$ ages (reforested soils) samples were obtained. 


\section{Results}

\subsection{The spatiotemporal patterns of alpha diversity}

After subsampling to 49011 sequences per sample, a total of 14703300 sequences (17409 OTUs) were retained. The number of OTUs estimated by Chao1 (17713 \pm 30$)$ and ACE $(17688 \pm 62)$ diversity indices was roughly equivalent to the total number of observed OTUs (17409) (Table S1). In our study, the abundant and rare OTUs were analyzed at two levels: local and regional. The local level was used for alpha diversity, and the regional level was used for beta diversity and community assembly. At the local level, the abundant OTUs were defined according to relative abundances of $>0.5 \%$ within a sample; OTUs with a relative abundance of $<0.01 \%$ were defined as "rare." Regionally, OTUs were defined as abundant if their mean relative abundance was $>0.05 \%$ in all samples; regionally rare OTUs were defined as having a mean relative abundance of $<0.001 \%$.

There was great taxonomic diversity in both the rare and abundant sub-communities at local level. The abundant and rare taxa were primarily Proteobacteria, Actinobacteria, and Acidobacteria. The top 10 phyla in terms of relative abundance were the same for the abundant and rare subcommunities, but the order was not consistent (Fig. S1). Moreover, the abundant and rare taxa exhibited different environmental associations (Fig. S2). For example, the abundance of abundant Proteobacteria was negatively correlated with soil total phosphorus (TP), while that of rare Proteobacteria was negatively correlated with soil $\mathrm{pH}$, TP, and available phosphorus (AP). The abundant bacterial taxa had a greater presence across the soil samples than the rare taxa. The relative abundance of the abundant taxa and the number of sites occupied were significantly positively correlated $(r=$ $0.263, P<0.001)$. The relative abundance of rare taxa was also positively correlated with site occupancy $(r=0.982$, $P<0.001$; Fig. S3). Some abundant OTUs occupied $100 \%$ of samples, but none of the rare OTUs were present in more than $40 \%$ of the samples.

The alpha diversities (richness and Shannon index) of both the abundant and rare bacteria were higher in the reforestation soils than in the farmland soils (Fig. S4). The linear mixedeffects models showed that the alpha diversity of the abundant and rare bacteria differed significantly with the progression of reforestation and soil depth but was not affected by the radius from the tree (Table S2). In addition, the alpha diversity of the rare bacteria exhibited greater differences during reforestation than that of the abundant bacteria; in contrast, the alpha diversity of the abundant bacteria showed larger variation across soil depth than rare bacteria (Table S2). Spearman's correlation analysis showed that the correlation of rare bacteria with TP and AP is higher than that of abundant bacteria, but the correlation with $\mathrm{pH}$ and nitrate $\left(\mathrm{NO}_{3}\right)$ is lower than that of abundant bacteria (Table S3). Soil TP was also identified by random forest model analysis to be the most important environmental factor affecting alpha diversity, regardless of abundant and rare bacteria (Fig. S5). The above results were based on the abundant and rare sub-communities at the local level.

\section{$3.2 \beta$-diversity and its key drivers}

Non-metric multidimensional scaling (NMDS) analysis showed that samples of the abundant and rare sub-communities clustered strongly according to chronosequence rather than to depth or radius from the tree (Table 1 and Fig. 2A). Compared with the abundant sub-communities, the beta diversity of rare sub-communities showed greater differences among the reforestation chronosequence sites but smaller differences among soil depths. This was confirmed by analyzing similarities (ANOSIM) (Table 1 and Fig. 2A). Meanwhile, almost no significant differences were observed between the different radii, except between $30 \mathrm{~cm}$ and $90 \mathrm{~cm}$ radii in the abundant sub-communities. The impact of the reforestation stage on the abundant and rare sub-communities was greatest in the topsoil and less significant in the deep soil (Table S4). Likewise, both the abundant and rare taxa exhibited greater community dissimilarities during the reforestation process in the $30 \mathrm{~cm}$ radius samples than in the $60 \mathrm{~cm}$ and $90 \mathrm{~cm}$ radii samples (Table S5).

Table 1 Analysis of similarity (ANOSIM) statistics testing differences of abundant and rare bacteria communities during reforestation.

\begin{tabular}{cccccc}
\hline & \multicolumn{2}{c}{ Abundant } & & \multicolumn{2}{c}{ Rare } \\
\cline { 2 - 3 } \cline { 5 - 6 } Year & $R$ & $P$ & & $R$ & $P$ \\
Farm-Y10 & 0.968 & $<0.001$ & & 0.915 & $<0.001$ \\
Farm-Y20 & 0.995 & $<0.001$ & & 0.925 & $<0.001$ \\
Farm-Y30 & 0.991 & $<0.001$ & & 0.995 & $<0.001$ \\
Y10-Y20 & 0.722 & $<0.001$ & & 0.869 & $<0.001$ \\
Y10-Y30 & 0.827 & $<0.001$ & & 0.895 & $<0.001$ \\
Y20-Y30 & 0.672 & $<0.001$ & & 0.843 & $<0.001$ \\
Depth & 0.030 & $<0.01$ & & 0.0002 & 0.423 \\
Top-Mid & 0.058 & $<0.001$ & & 0.006 & 0.208 \\
Top-Deep & 0.035 & $<0.05$ & & -0.004 & 0.618 \\
Mid-Deep & 0.009 & 0.203 & & 0.003 & 0.330 \\
Radius & 0.005 & 0.133 & & 0.002 & 0.291 \\
R30-R60 & -0.004 & 0.733 & & 0.001 & 0.425 \\
R30-R90 & 0.015 & $<0.05$ & & -0.002 & 0.568 \\
R60-R90 & 0.007 & 0.124 & & -0.002 & 0.621 \\
\hline
\end{tabular}

Note: Abundant, abundant bacteria; Rare, rare bacteria. Farm, farmland; Y10, 10 year forest; Y20, 20 year forest; Y30, 30 year forest. Top, top layer; Mid, middle layer; Deep, deep layer. R30, $30 \mathrm{~cm}$ radius around the trunk; $R 60,60 \mathrm{~cm}$ radius around the trunk; $R 90,90$ $\mathrm{cm}$ radius around the trunk. 

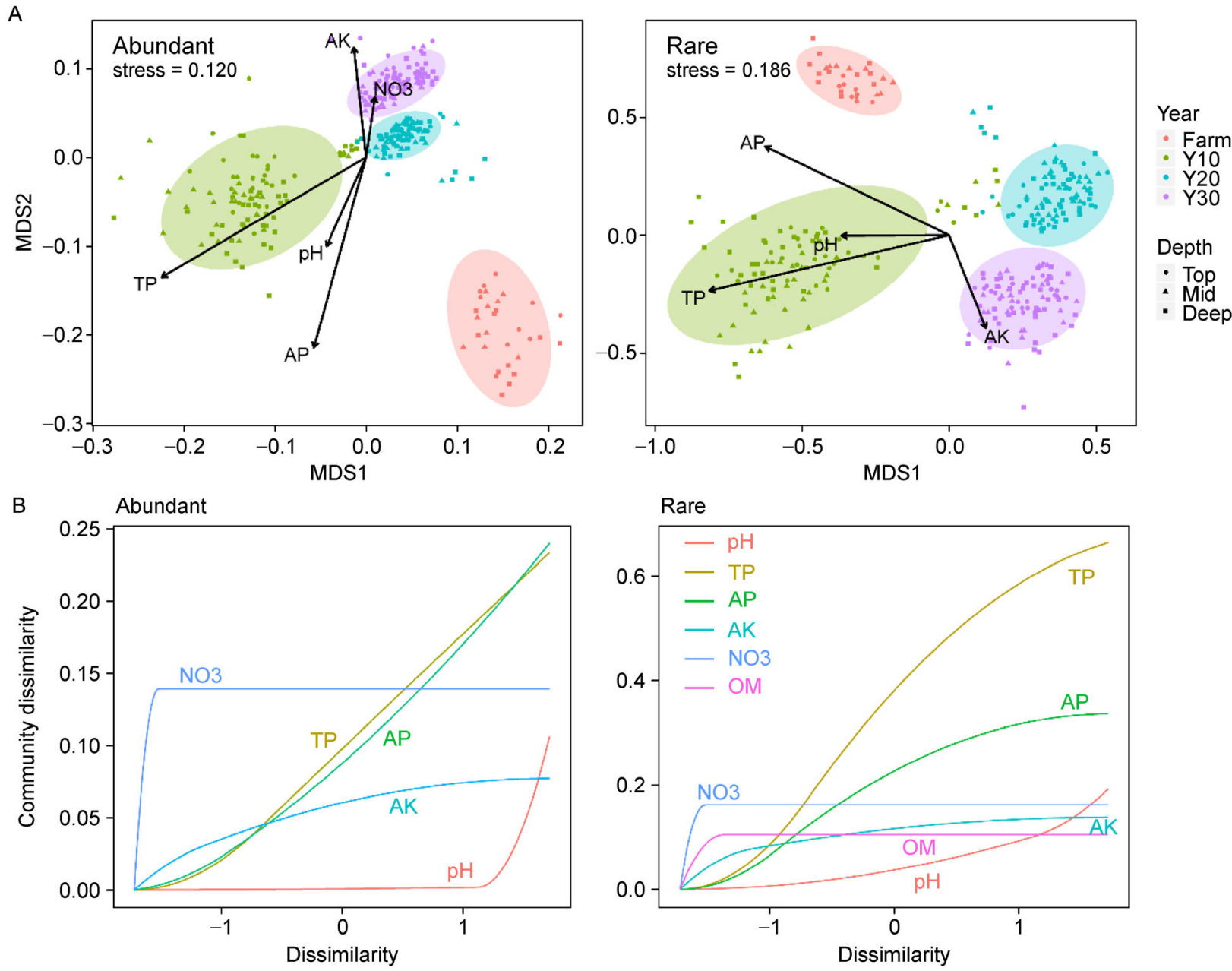

Fig. 2 Community structure patterns of abundant and rare bacteria during reforestation. (A) Non-metric multidimensional scaling (NMDS) ordination based on Bray-Curtis similarity. The vectors were added post hoc and are based on the envfit analysis. Samples in the four successional stages with three layers (top, middle and deep). Farm, farmland; Y10, 10 year forest; Y20, 20 year forest; Y30, 30 year forest. Top, top layer; Mid, middle layer; Deep, deep layer. (B) Generalized dissimilarity models of abundant and rare bacterial communities with environmental factors. Only significant variables are plotted. Abundant, abundant bacteria; Rare, rare bacteria. The abbreviations of environmental variables are defined in Methods.

The contributions of environmental and geographic factors to variations in each sub-community structure were quantified using the Mantel and partial Mantel tests (Table S6). Spatial factors had a stronger influence on the abundant subcommunities variations than environmental factors, whereas environmental factors had a greater impact on the rare subcommunities compared with spatial factors (Table S6). To deal with the relative contributions of environmental drivers on the abundant and rare bacterial community composition, GDMs was fitted and explained $34 \%$ of the variation in the abundant bacterial community composition and $47 \%$ of the variation in the rare bacterial community composition. TP and AP explained the largest proportion of the abundant bacterial community turnover (coefficient $=0.140$ ), and the rare bacterial also showed similar trends (TP: coefficient $=0.582$; AP: coefficient $=0.336)($ Fig. $2 B$ and Table 2). The abundant and rare bacterial community dissimilarity also highly varied with small changes in $\mathrm{NO}_{3}$, but dissimilarity reached a plateau rapidly (Fig. 2B and Table 2). To complement our findings from GDMs, this was also determined using "envfit" and distancebased linear modeling, which found TP and AP to be the most important factors influencing the structures of both the abundant and rare sub-communities (Fig. 2A, Table S7, and Table S8). The analysis related to beta diversity was based on the abundant and rare sub-communities at the regional level.

\subsection{Community assembly process and its key drivers}

To evaluate the community assembly mechanism of the abundant and rare bacteria at the regional level during reforestation, the method represented by the null model is used. The mean standardized effect size of mean nearest taxon distance (SES.MNTD) values was significantly lower for 
Table 2 Results of generalized dissimilarity modeling (GDM) on abundant and rare bacterial community composition. Only predictors that were retained as significant in model selection are included.

\begin{tabular}{ll}
\hline Abundant bacteria & $\begin{array}{l}\text { Deviance explained }= \\
0.34 \text { Coefficients }\end{array}$ \\
\hline $\mathrm{pH}$ & 0.110 \\
Nitrate & 0.139 \\
Total phosphorus & 0.140 \\
Available phosphorus & 0.140 \\
Available potassium & 0.056 \\
\hline \hline Rare bacteria & Deviance explained $=$ \\
\hline pH & 0.47 Coefficients \\
Organic matter & 0.123 \\
Nitrate & 0.105 \\
Total phosphorus & 0.162 \\
Available phosphorus & 0.582 \\
Available potassium & 0.336 \\
\hline
\end{tabular}

the rare taxa than for the abundant taxa (Wilcoxon rank-sum test, $P<0.001)$. This suggests that more phylogenetic clustering was displayed by rare taxa than by abundant taxa (Fig. 3A). By quantifying the relative contributions of each assembly process during the reforestation process, we found that the abundant sub-communities were primarily influenced by stochastic processes $(63.96 \%)$, while deterministic processes $(60.83 \%)$ were dominant in the rare sub-communities (Fig. 3B). Dispersal limitation contributed a larger fraction to the assembly of the abundant sub-community $(63.73 \%)$ than the rare sub-community $(25.43 \%)$; whereas, the rare subcommunity was governed by homogeneous selection (58.73\%) (Fig. 3B).

To estimate changes in the assembly processes of each sub-community with the progression of the chronosequence, the $\beta \mathrm{NTI}$ distributions were examined over the successional reforestation stages (Fig. S6 and Fig. S7). In the abundant sub-communities, the influence of stochastic processes decreased with the successional stage. In contrast, stochasticity first increased and then declined in the rare subcommunities. Moreover, the relationships between the assembly processes of the abundant and rare sub-communities and the soil depths and horizontal distances were investigated (Fig. 4 and Fig. S8). The assembly of rare subcommunities changed remarkably with soil depth; the influence of stochastic processes gradually increased with soil depth in the rare sub-communities, and no such trend was observed for the abundant sub-communities (Fig. 4A). Meanwhile, in terms of the horizontal distance, the influence of deterministic processes increased in abundant sub-communities with increasing radius from a single tree (Fig. 4B). In contrast, stochastic processes provided the largest contribu-
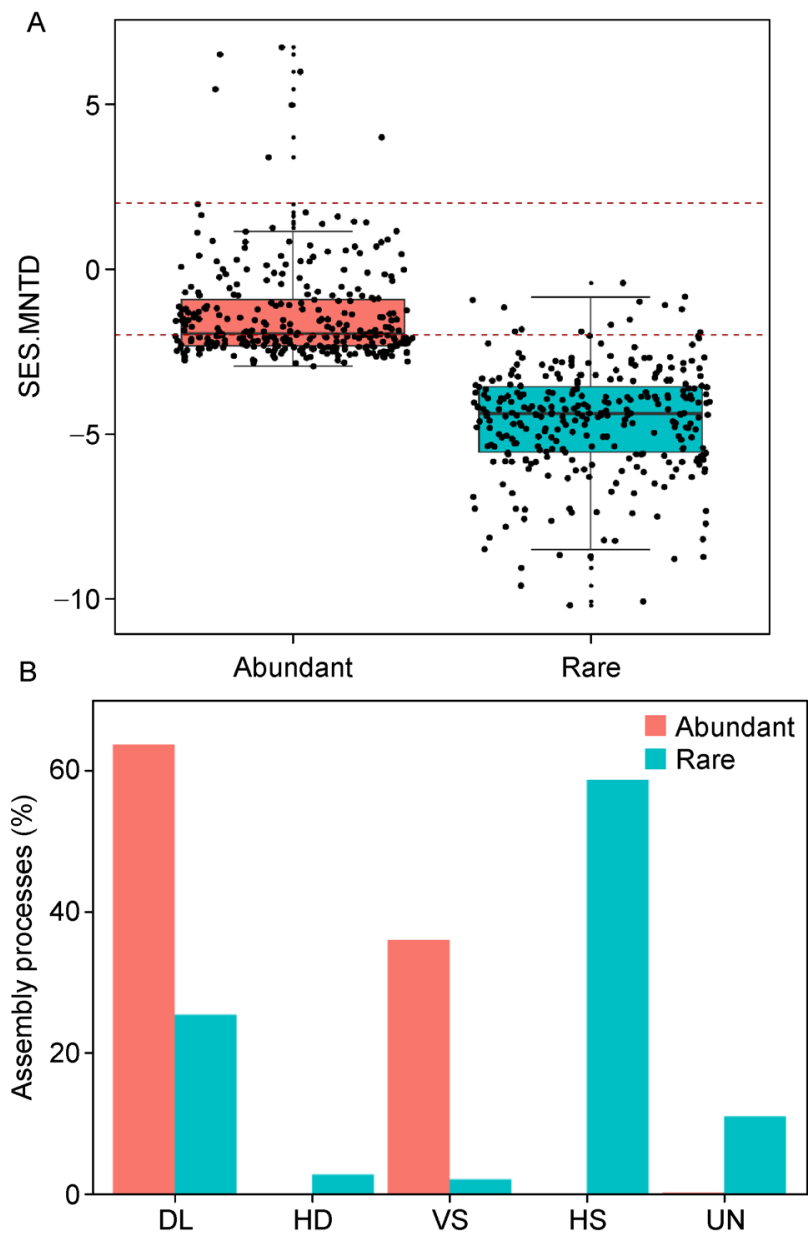

Fig. 3 The percent of turnover in abundant and rare bacterial community assembly in reforestation. (A) Boxplot showing difference in SES.MNTD values between abundant and rare sub-communities. (B) The per cent of turnover in abundant and rare bacterial community assembly governed primarily by various deterministic, including homogeneous and variable selection, and stochastic processes, including dispersal limitations and homogenizing dispersal, as well as the fraction that was not dominated by any single process ('Undominated') in successional soils. DL, diserpal limitation; HD, homogenizing dispersal; VS, variable selection; HS, homogeneous selection; UN, undominated.

tion to the assembly of rare sub-communities at the radius of $60 \mathrm{~cm}$ from the trunk (Fig. 4B).

The relationships between the $\beta \mathrm{NTI}$ values and major environmental variables were used to estimate changes in the relative influences of deterministic and stochastic assembly processes. The Mantel test results showed that soil TP was the best predictor of assembly processes for both the abundant and rare sub-communities (Table 3). Partial Mantel tests confirmed that the relationships remained significant after controlling spatial distance and other measured environmental variables (Table S9). Pairwise comparisons of $\beta$ NTI values both within and among reforestation stages for the abundant and rare sub-communities were significantly and positively correlated to differences in soil TP (Fig. S9). This 

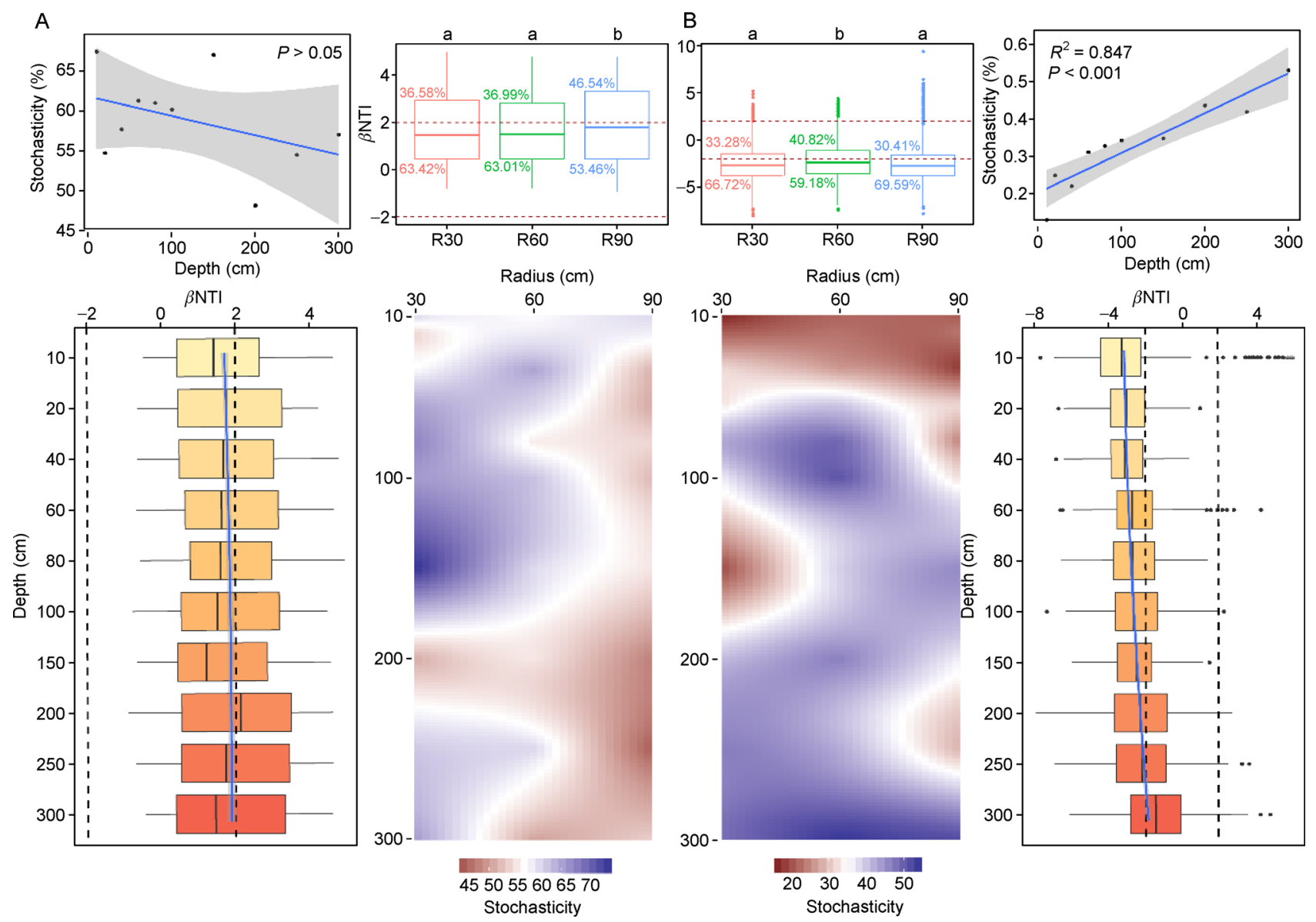

Fig. 4 Community assembly of abundant $(\mathrm{A})$ and rare $(\mathrm{B})$ communities in the horizontal and vertical soil profiles. $\mathrm{R} 30,30 \mathrm{~cm}$ radius around the trunk; $R 60,60 \mathrm{~cm}$ radius around the trunk; $R 90,90 \mathrm{~cm}$ radius around the trunk.

result indicated that soil TP predominately mediated the assembly of abundant and rare sub-communities during the reforestation process.

The samples were further divided into different soil TP categories and correlated with the $\beta \mathrm{NTI}$ values (Fig. 5). In the abundant sub-communities, as TP increased, the relative influence of stochasticity increased, shifting from the variable selection. In the rare sub-communities, the relative influence of stochasticity also increased with TP, while there was a shift from homogeneous selection to stochasticity (Fig. 5 and Fig. S10).

\section{Discussion}

Revealing community assembly processes during ecological succession is essential for understanding how biological communities generate and respond to environmental change (Nemergut et al., 2013; Zhou and Ning, 2017). This, in turn, is crucial for maintaining ecosystem functions (Jing et al., 2015; Delgado-Baquerizo et al., 2016). The results of this study shed light on the assembly patterns of the abundant and rare sub-communities of bacteria. The results also show how community assembly was regulated during secondary succession over horizontal and vertical soil profiles. It was found that the abundant and rare sub-communities exhibited distinct and complex spatiotemporal community assembly patterns during ecological succession. Furthermore, assembly strategies of both the abundant and rare sub-communities were mediated by soil phosphorus.

4.1 Abundant and rare bacteria exhibited different spatiotemporal patterns along the reforestation

The abundant taxa were more universally observed than the rare taxa. This supports the view that the abundant taxa occupy diverse niches, competitively utilize a chain of resources, and are more adaptable to changing environments (Jiao et al., 2017a). Meanwhile, the rare taxa in this study were restricted by habitat specificity (Barberán et al., 2014; Jousset et al., 2017) and could become the abundant taxa under suitable conditions such as in highly diverse soil "seed banks" (Lennon and Jones, 2011). Our result agreed with another study of ours in agricultural fields that the abundant taxa exhibited broader response thresholds across environmental gradients compared to the rare taxa (Jiao and Lu, 2020). 

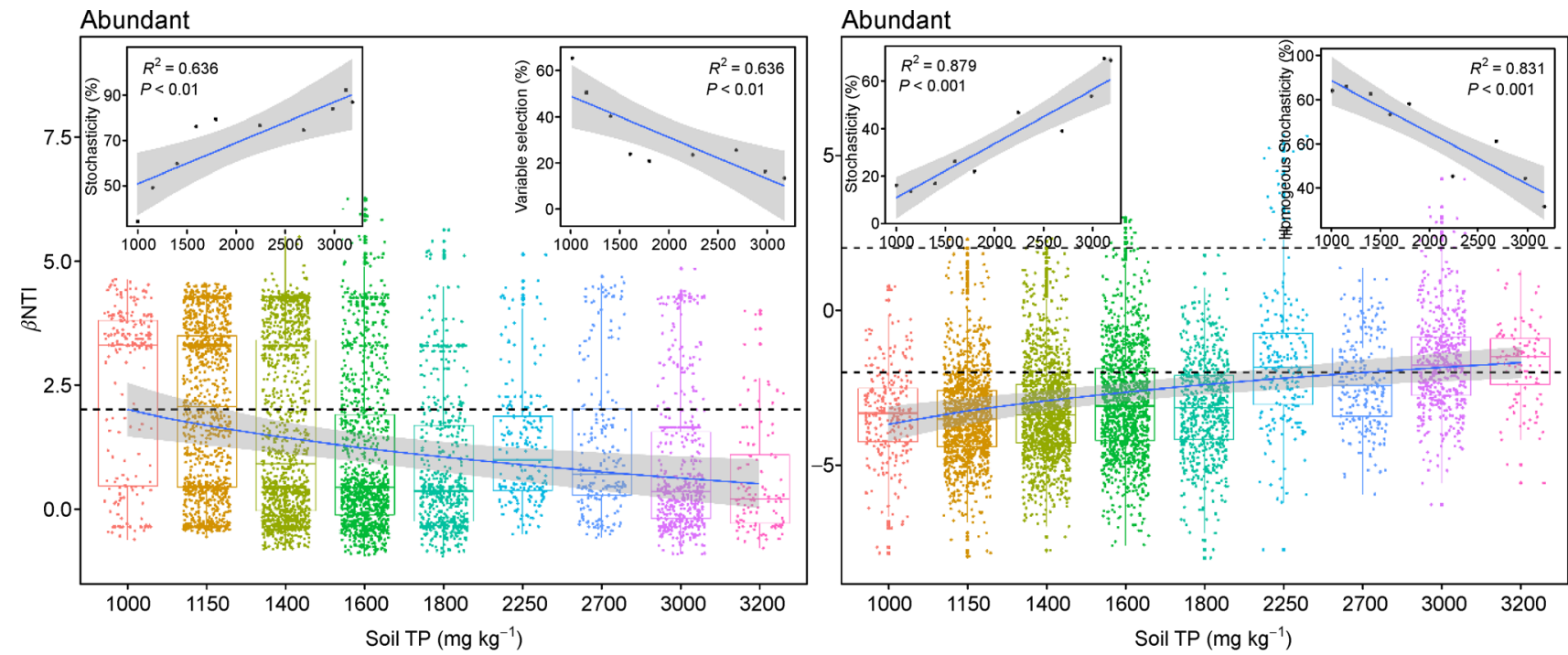

Fig. 5 Patterns of $\beta \mathrm{NTI}$ across different categories in soil total phorphous for the abundant and rare sub-communities. The lines denote the least-squares linear regressions across soil phorphous, with their $95 \%$ confidence intervals (gray-shaded areas). TP: total phosphorus.

Table 3 Mantel test of environmental variables against the phylogenetic turnover ( $\beta$-nearest taxon index) of abundant and rare subcommunities in reforestation successional soils.

\begin{tabular}{|c|c|c|}
\hline & Abundant & Rare \\
\hline Spatial & -0.024 & $0.095^{\star \star *}$ \\
\hline Environmental & $0.066^{*}$ & $0.165^{\star * \star}$ \\
\hline $\mathrm{pH}$ & $0.054^{*}$ & -0.078 \\
\hline OM & -0.002 & -0.040 \\
\hline NO3 & 0.017 & -0.066 \\
\hline TP & $0.167^{* * *}$ & $0.385^{\star * *}$ \\
\hline AP & -0.076 & $0.361^{\star \star *}$ \\
\hline AK & $0.142^{* * *}$ & -0.036 \\
\hline
\end{tabular}

Note: The abbreviations of environmental variables are defined in Methods. * $P<0.05 ;{ }^{* *}, P<0.01 ;{ }^{* * *}, P<0.001$.

Interestingly, rare bacteria showed a more significantly positive abundance-occupancy relationship compared with abundant bacteria, which was due to the high abundance of abundant bacteria occupying almost the whole reforestation soils.

As the succession progressed, the alpha diversities of both the abundant and rare taxa increased. This thereby promotes the functional redundancy of later successional soils (Caron and Countway, 2009), and ecosystems are gradually becoming more stable along with succession (Morriën et al., 2017). In addition, the rare sub-communities showed greater differences in both diversity and composition than the abundant sub-communities among the different reforestation stages. This conclusion is supported by the previous finding that there was a highly dynamic turnover of rare species following a reservoir cyanobacterial bloom (Xue et al., 2018). Meanwhile, the alpha diversity and community composition of the abundant taxa differed more in response to soil depth. This suggested that the abundant taxa responded more strongly to soil depth than rare taxa. This may be explained by the fact that the abundant taxa were mainly affected by dispersal limitation compared with the rare taxa, which results in low migration rates (Evans et al., 2017). It was also observed that the structures of the abundant and rare sub-communities in deep soils and at the $90 \mathrm{~cm}$ radius differed less than those of the communities in the upper soil layers and at the $30 \mathrm{~cm}$ radius from a single tree. This indicated that plants significantly affected the bacterial community composition irrespective of whether the taxa were abundant or rare (Marschner et al., 2001). Moreover, the greater the distance from the tree trunk, the less influence the plants had on the bacterial communities, as previously observed by Nacke et al. (2016).

4.2 Different assembly processes of abundant and rare bacteria sub-communities

Quantifying the contributions of deterministic and stochastic processes to microbial community assembly is an important research area in microbial ecology (Nemergut et al., 2013; Zhou and Ning, 2017). A null model analysis, incorporating phylogenetic and taxonomic beta diversity, provides a systematic framework for inferring community assembly mechanisms (Stegen et al., 2013; Zhou and Ning, 2017). In the present study, the homogeneous selection was found to be the main process driving the assembly of the rare subcommunities during the reforestation process, while dispersal limitation was a significant process affecting the abundant sub-communities. Moreover, the rare taxa with lower SES. MNTD values were more closely phylogenetically clustered than the abundant taxa, verifying that environmental filtering 
causes phylogenetic clustering (Cavender-Bares et al., 2009). This result was in line with a previous study in agricultural soils (Jiao and Lu, 2020). However, the result contradicts studies performed in oil-contaminated soils (Jiao et al., 2017a) and subtropical bays (Mo et al., 2018). Such discrepancies could be due to the differences in habitat and geography (Shi et al., 2018).

In line with hypothesis $\mathrm{i}$, the relative influence of deterministic processes was observed to increase with succession (both abundant and rare sub-communities). Disturbance due to afforestation may generate heterogenetic soil habitats with many opportunities for successful immigration. These results are also supported by a study that found that the deterministic selection became increasingly strong toward later successional stages in a salt marsh chronosequence (Dini-Andreote et al., 2015). However, a meta-analysis has shown that changes in bacterial community assembly with the progression of succession exhibit different trends among ecosystems (Tripathi et al., 2018). This difference may be related to the type of succession and local environmental conditions.

In addition to the succession gradient, there are vertical and horizontal gradients of the soil profile in the succession ecosystem. Our study provides a deeper understanding of how soil vertical and horizontal profiles affect community assembly of the abundant and rare bacteria. We found that the deeper the soil, the greater the influence of stochastic assembly processes on the rare sub-communities. Meanwhile, for the abundant sub-communities, the greater the distance from the trunk, the greater the influence of deterministic assembly processes. A plausible explanation for this is that the abundant taxa, as habitat generalists, occupy diverse niches that are mainly regulated by soil nutrient elements rather than by niche differences (Monard et al., 2016; Jiao et al., 2017b); meanwhile, the rare taxa are restricted by habitat specificity (Barberán et al., 2014; Jousset et al., 2017). Due to the negative relationships between fine root biomass and litter with tree distance (Nacke et al., 2016), more nutrients and fewer niches in the soil located close to tree trunks promote an increase in stochastic processes. Compared to the low number of niches in deep soils, the greater number of niches in surface soils created by root activity and complex litter components (Peng et al., 2004) leads to a greater influence of deterministic processes.

\subsection{Soil phosphorus drives distinct assembly strategies for} abundant and rare bacteria

The further extended understanding of community assembly reveals factors affecting the relative influences of stochastic and deterministic processes that govern the assembly of microbial communities (Tripathi et al., 2018). As we know, environment variables are to affect bacterial community composition and diversity during both short-term (DiniAndreote et al., 2014; Rime et al., 2015; Zhang et al., 2016) and long-term (Jangid et al., 2013) succession. Similarly, several studies have shown that environmental factors, such as soil pH (Tripathi et al., 2018) and OM (Dini-Andreote et al., 2015), play an important role in influencing bacterial community assembly processes during ecological succession. Interestingly, soil total phosphorus mediated the balance between stochastic and deterministic assembly processes for the abundant and rare bacteria, while the community assembly of abundant and rare bacteria had distinct response strategies to total phosphorus during successional reforestation. As a major nutritional constraint for primary production in terrestrial ecosystems (Cleveland et al., 2013), soil phosphorus content cannot be quickly replenished as it is primarily obtained from rock weathering (Walker and Adams, 1958; Li et al., 2019). And this further affects the dynamics of soil $\mathrm{C}$ stocks (Shi et al., 2016) and nitrogen cycling (Vitousek et al., 2010). In addition, soil $P$ concentration in the Loess Plateau is lower on average than the global mean, which exacerbate soil $P$ as the main limiting factor (Li et al., 2019). Previous research has shown that soil phosphorus significantly influenced the structure and diversity of the soil microbial community in Loess Plateau ecosystems (Jangid et al., 2013; Chen et al., 2014; Li et al., 2019; Randall et al., 2019). Moreover, since our samples are collected around the twodimensional space (vertical and horizontal) of the soil profile of a single tree, the role of soil phosphorus in regulating community assembly of the abundant and rare bacteria may be amplified by the rhizosphere effect of plants because phosphorus is the main nutrient of plants. The rhizosphere effect also explains that the rare taxa that were more closely phylogenetically clustered under selective enrichment strongly correlate with soil phosphorus than the abundant taxa.

The present study results showed that as soil phosphorus content increases, the assembly processes of the abundant sub-communities gradually shifted from variable selection to stochastic processes. Meanwhile, the assembly processes of rare sub-communities gradually changed from homogeneous selection to stochastic processes as soil phosphorus content increased. In a low-phosphorus environment where phosphorus is the main limiting factor, it is possible that other nutrient elements differently select the abundant adaptive bacteria, while the rare bacteria cannot use other nutrients. The predominance of stochasticity in high-phosphorus environments might be explained by high phosphorus resulting in weaker niche rejection and increasing the arrival of bacterial lineages (Chase, 2010; Dai et al., 2020). These findings support the resource supply-stochasticity relationship put forward by Dini-Andreote et al. (2015); a high resource supply can increase stochasticity under physicochemical conditions that do not impose strong selection. Overall, the results showed that soil phosphorus mediated the balance of the deterministic and stochastic processes underlying the assembly of the abundant and rare bacterial communities, while community assembly processes of the abundant and rare communities responded differently to phosphorus. 

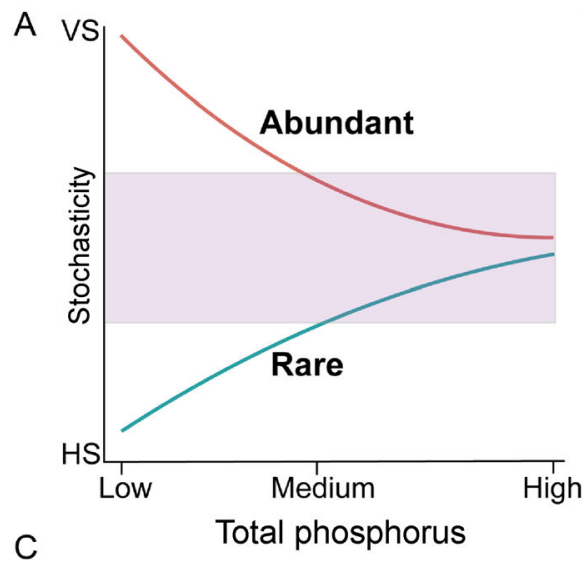

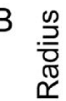

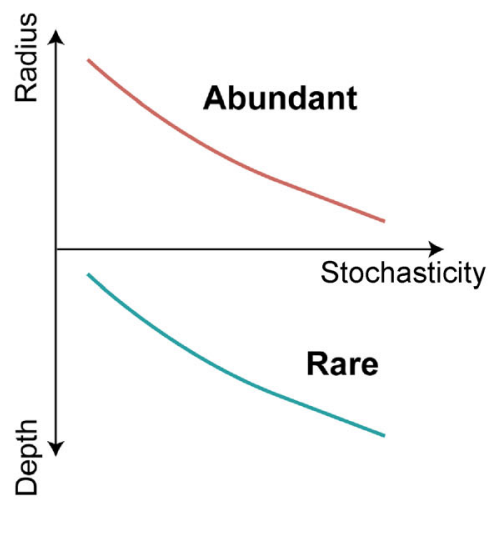

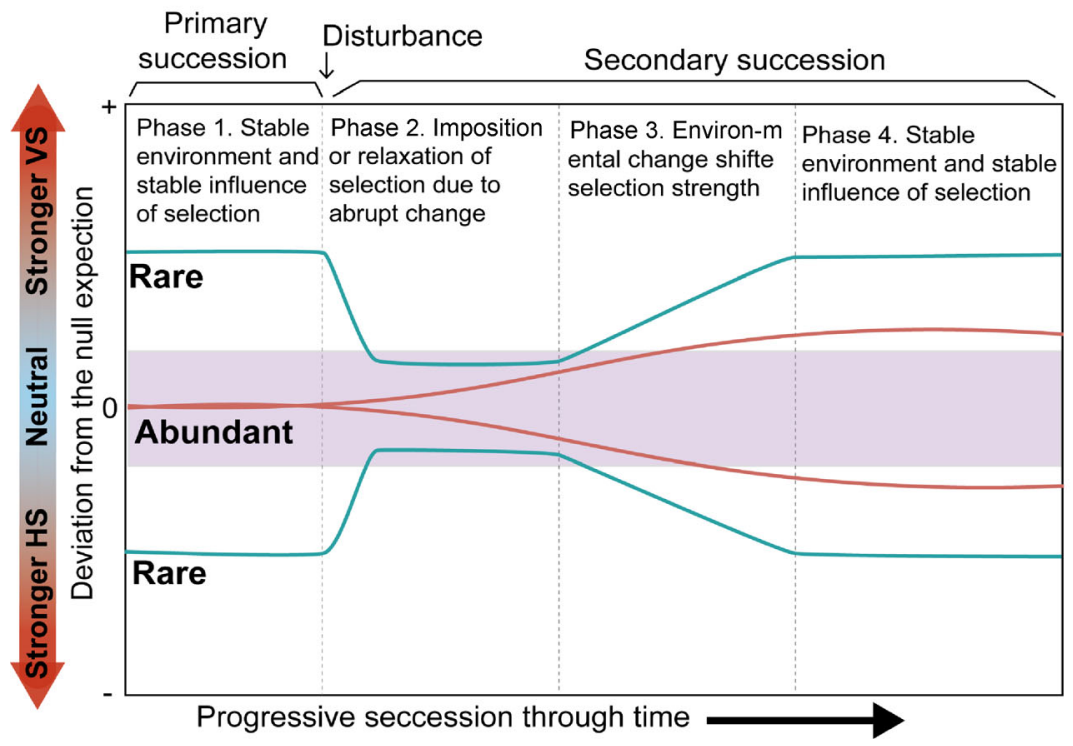

Fig. 6 Conceptual paradigm showing assembly processes of abundant and rare bacterial community along successional soils with changing in (A) soil total phorphous (TP), (B) soil profiles, and (C) temporal trajectory. HS, homogeneous selection; VS, variable selection.

\section{Conclusion}

In this study, we propose a conceptual paradigm (Fig. 6) to elucidate the balance of stochastic and deterministic assembly processes underlying abundant and rare bacterial subcommunities in relation to soil phosphorus, during succession and across horizontal and vertical soil profiles. First, higher phosphorus leads to more stochastic assembly for the abundant and rare bacteria, while low phosphorus led to more variable selection for the abundant communities and more homogenous selection for the rare communities. Second, distinct processes drive the abundant and rare bacteria assembly strategies along restoration stages and soil profiles. This conceptual paradigm extends the previous model to abundant and rare communities. Considering the importance of the abundant and rare taxa for overall ecosystem functioning, it is crucial to understanding the mechanisms underpinning the generation and maintenance of abundant and rare bacteria in response to environmental gradients. By uncovering the intrinsic linkages between assembly processes and soil phosphorus, the present study could facilitate the management of bacterial communities in reforestation for better adaptation to habitat fragmentation and environment change.

\section{Author contributions}

We are thankful to all authors for their help in this study. All authors contributed intellectual input and assistance to experiments and the manuscript preparation. Z.P. conducted the experiments, analyzed the data, and wrote the manuscript. G.W. and S.J. conceived and designed the experiments and revised the manuscript. Z.W., Y.L., M.Y., T,Y., M.C., and W.C. conducted field and laboratory work.

\section{Acknowledgments}

This work was supported by the National Science Foundation of China (Grant Nos.: 42077222, 41807030 and 41830755). 


\section{Conflict of interest}

The authors have no conflicts of interest to declare.

\section{Electronic supplementory material}

Supplementary material is available in the online version of this article at http://doi.org/10.1007/s42832-021-0109-z and is accessible for authorized users.

\section{References}

Archer, E. 2016. rfPermute: Estimate permutation p-values for Random Forest importance metrics. $R$ package version 1.

Bao, S., 2000. Soil Agrochemical Analysis. China Agricultural Press, Beijing, 25-114.

Barberán, A., Ramirez, K.S., Leff, J.W., Bradford, M.A., Wall, D.H., Fierer, N., 2014. Why are some microbes more ubiquitous than others? Predicting the habitat breadth of soil bacteria. Ecology Letters 17, 794-802.

Bardgett, R., 2005. The biology of soil: a community and ecosystem approach. Oxford university press.

Bates, D., Mächler, M., Bolker, B., Walker, S., 2015. Fitting linear mixed-effects models using Ime4. Journal of Statistical Software $67,48$.

Caporaso, J.G., Lauber, C.L., Walters, W.A., Berg-Lyons, D., Lozupone, C.A., Turnbaugh, P.J., Fierer, N., Knight, R., 2011. Global patterns of $16 \mathrm{~S}$ rRNA diversity at a depth of millions of sequences per sample. Proceedings of the National Academy of Sciences of the United States of America 108, 4516-4522.

Caron, D.A., Countway, P.D., 2009. Hypotheses on the role of the protistan rare biosphere in a changing world. Aquatic Microbial Ecology 57, 227-238.

Cavender-Bares, J., Kozak, K.H., Fine, P.V.A., Kembel, S.W., 2009. The merging of community ecology and phylogenetic biology. Ecology Letters 12, 693-715.

Chang, C., HilleRisLambers, J., 2016. Integrating succession and community assembly perspectives. F1000 Research 5, 5 .

Chang, C.C., Turner, B.L., 2019. Ecological succession in a changing world. Journal of Ecology 107, 503-509.

Chase, J.M., 2010. Stochastic community assembly causes higher biodiversity in more productive environments. Science 328, 1388 1391

Chave, J., 2004. Neutral theory and community ecology. Ecology Letters 7, 241-253.

Chen, D., Saleem, M., Cheng, J., Mi, J., Chu, P., Tuvshintogtokh, I., $\mathrm{Hu}$, S., Bai, Y., 2019a. Effects of aridity on soil microbial communities and functions across soil depths on the Mongolian Plateau. Functional Ecology 33, 1561-1571.

Chen, W., Jiao, S., Li, Q., Du, N., 2019b. Dispersal limitation relative to environmental filtering governs the vertical small-scale assembly of soil microbiomes during restoration. Journal of Applied Ecology $57,402-412$.

Chen, X., Daniell, T.J., Neilson, R., O'Flaherty, V., Griffiths, B.S., 2014. Microbial and microfaunal communities in phosphorus limited, grazed grassland change composition but maintain homeostatic nutrient stoichiometry. Soil Biology \& Biochemistry 75, 94-101.

Chiquoine, L.P., Abella, S.R., Bowker, M.A., 2016. Rapidly restoring biological soil crusts and ecosystem functions in a severely disturbed desert ecosystem. Ecological Applications 26, 12601272.

Cleveland, C.C., Houlton, B.Z., Smith, W.K., Marklein, A.R., Reed, S. C., Parton, W., Del Grosso, S.J., Running, S.W., 2013. Patterns of new versus recycled primary production in the terrestrial biosphere. Proceedings of the National Academy of Sciences of the United States of America 110, 12733-12737.

Dai, Z., Liu, G., Chen, H., Chen, C., Wang, J., Ai, S., Wei, D., Li, D., Ma, B., Tang, C., Brookes, P.C., Xu, J., 2020. Long-term nutrient inputs shift soil microbial functional profiles of phosphorus cycling in diverse agroecosystems. ISME Journal 14, 757-770.

Delgado-Baquerizo, M., Maestre, F.T., Reich, P.B., Jeffries, T.C., Gaitan, J.J., Encinar, D., Berdugo, M., Campbell, C.D., Singh, B.K., 2016. Microbial diversity drives multifunctionality in terrestrial ecosystems. Nature Communications 7, 10541.

Dini-Andreote, F., de Cássia Pereira e Silva, M., Triadó-Margarit, X., Casamayor, E.O., van Elsas, J.D., Salles, J.F., 2014. Dynamics of bacterial community succession in a salt marsh chronosequence: evidences for temporal niche partitioning. ISME Journal 8, 1989 2001.

Dini-Andreote, F., Stegen, J.C., van Elsas, J.D., Salles, J.F., 2015. Disentangling mechanisms that mediate the balance between stochastic and deterministic processes in microbial succession. Proceedings of the National Academy of Sciences of the United States of America 112, E1326-E1332.

Edgar, R.C., Haas, B.J., Clemente, J.C., Quince, C., Knight, R., 2011. UCHIME improves sensitivity and speed of chimera detection. Bioinformatics (Oxford, England) 27, 2194-2200.

Eilers, K.G., Debenport, S., Anderson, S., Fierer, N., 2012. Digging deeper to find unique microbial communities: The strong effect of depth on the structure of bacterial and archaeal communities in soil. Soil Biology \& Biochemistry 50, 58-65.

Evans, S., Martiny, J.B.H., Allison, S.D., 2017. Effects of dispersal and selection on stochastic assembly in microbial communities. ISME Journal 11, 176-185.

Fargione, J., Brown, C.S., Tilman, D., 2003. Community assembly and invasion: an experimental test of neutral versus niche processes. Proceedings of the National Academy of Sciences of the United States of America 100, 8916-8920.

Ferrenberg, S., O'Neill, S.P., Knelman, J.E., Todd, B., Duggan, S., Bradley, D., Robinson, T., Schmidt, S.K., Townsend, A.R., Williams, M.W., Cleveland, C.C., Melbourne, B.A., Jiang, L., Nemergut, D.R., 2013. Changes in assembly processes in soil bacterial communities following a wildfire disturbance. ISME Journal 7, 1102-1111.

Fierer, N., Nemergut, D., Knight, R., Craine, J.M., 2010. Changes through time: integrating microorganisms into the study of succession. Research in Microbiology 161, 635-642.

Fierer, N., Schimel, J.P., Holden, P.A., 2003. Variations in microbial community composition through two soil depth profiles. Soil Biology \& Biochemistry 35, 167-176.

Fukami, T., 2015. Historical contingency in community assembly: 
Integrating niches, species pools, and priority effects. Annual Review of Ecology, Evolution, and Systematics 46, 1-23.

Gao, G.F., Peng, D., Tripathi, B.M., Zhang, Y., Chu, H., 2020. Distinct community assembly processes of abundant and rare soil bacteria in coastal wetlands along an inundation gradient. mSystems 5 , e01150-e01120.

Glassman, S.I., Wang, I.J., Bruns, T.D., 2017. Environmental filtering by $\mathrm{pH}$ and soil nutrients drives community assembly in fungi at fine spatial scales. Molecular Ecology 26, 6960-6973.

Goslee, S.C., Urban, D.L., 2007. The ecodist Package for Dissimilarity-based Analysis of Ecological Data. Journal of Statistical Software 22, 1-19.

Hartmann, M., Lee, S., Hallam, S.J., Mohn, W.W., 2009. Bacterial, archaeal and eukaryal community structures throughout soil horizons of harvested and naturally disturbed forest stands. Environmental Microbiology 11, 3045-3062.

HilleRisLambers, J., Adler, P.B., Harpole, W.S., Levine, J.M., Mayfield, M.M., 2012. Rethinking Community Assembly through the Lens of Coexistence Theory. Annual Review of Ecology, Evolution, and Systematics 43, 227-248.

Hou, J., Wu, L., Liu, W., Ge, Y., Mu, T., Zhou, T., Li, Z., Zhou, J., Sun, X., Luo, Y., Christie, P., 2020. Biogeography and diversity patterns of abundant and rare bacterial communities in rice paddy soils across China. Science of the Total Environment 730, 139116.

Jangid, K., Whitman, W.B., Condron, L.M., Turner, B.L., Williams, M. A., 2013. Soil bacterial community succession during long-term ecosystem development. Molecular Ecology 22, 3415-3424.

Jiao, S., Chen, W., Wang, J., Du, N., Li, Q., Wei, G., 2018. Soil microbiomes with distinct assemblies through vertical soil profiles drive the cycling of multiple nutrients in reforested ecosystems. Microbiome 6, 146.

Jiao, S., Chen, W., Wei, G., 2017a. Biogeography and ecological diversity patterns of rare and abundant bacteria in oil-contaminated soils. Molecular Ecology 26, 5305-5317.

Jiao, S., Lu, Y., 2020. Abundant fungi adapt to broader environmental gradients than rare fungi in agricultural fields. Global Change Biology 26, 4506- 4520.

Jiao, S., Lu, Y., 2020. Soil pH and temperature regulate assembly processes of abundant and rare bacterial communities in agricultural ecosystems. Environmental Microbiology 22, 10521065.

Jiao, S., Luo, Y., Lu, M., Xiao, X., Lin, Y., Chen, W., Wei, G., 2017b. Distinct succession patterns of abundant and rare bacteria in temporal microcosms with pollutants. Environmental Pollution 225, 497-505.

Jing, X., Sanders, N.J., Shi, Y., Chu, H., Classen, A.T., Zhao, K., Chen, L., Shi, Y., Jiang, Y., He, J.S., 2015. The links between ecosystem multifunctionality and above- and belowground biodiversity are mediated by climate. Nature Communications 6, 8159.

Jousset, A., Bienhold, C., Chatzinotas, A., Gallien, L., Gobet, A., Kurm, V., Küsel, K., Rillig, M.C., Rivett, D.W., Salles, J.F., van der Heijden, M.G.A., Youssef, N.H., Zhang, X., Wei, Z., Hol, W.H.G., 2017. Where less may be more: how the rare biosphere pulls ecosystems strings. ISME Journal 11, 853-862.

Kembel, S.W., Cowan, P.D., Helmus, M.R., Cornwell, W.K., Morlon, H., Ackerly, D.D., Blomberg, S.P., Webb, C.O., 2010. Picante: R tools for integrating phylogenies and ecology. Bioinformatics (Oxford, England) 26, 1463-1464.

Kuznetsova, A., Brockhoff, P.B., Christensen, R.H.B., 2017. ImerTest Package: Tests in linear mixed effects models. Journal of Statistical Software 82, 1-26.

Lennon, J.T., Jones, S.E., 2011. Microbial seed banks: the ecological and evolutionary implications of dormancy. Nature Reviews. Microbiology 9, 119-130.

Li, X., Li, Y., Peng, S., Chen, Y., Cao, Y., 2019. Changes in soil phosphorus and its influencing factors following afforestation in Northern China. Land Degradation \& Development 30, 16551666.

Liu, L., Yang, J., Yu, Z., Wilkinson, D.M., 2015. The biogeography of abundant and rare bacterioplankton in the lakes and reservoirs of China. ISME Journal 9, 2068-2077.

Lynch, M.D.J., Neufeld, J.D., 2015. Ecology and exploration of the rare biosphere. Nature Reviews. Microbiology 13, 217-229.

Marschner, P., Yang, C.H., Lieberei, R., Crowley, D.E., 2001. Soil and plant specific effects on bacterial community composition in the rhizosphere. Soil Biology \& Biochemistry 33, 1437-1445.

Mo, Y., Zhang, W., Yang, J., Lin, Y., Yu, Z., Lin, S., 2018. Biogeographic patterns of abundant and rare bacterioplankton in three subtropical bays resulting from selective and neutral processes. ISME Journal 12, 2198-2210.

Monard, C., Gantner, S., Bertilsson, S., Hallin, S., Stenlid, J., 2016. Habitat generalists and specialists in microbial communities across a terrestrial-freshwater gradient. Scientific Reports 6, 37719.

Morriën, E., Hannula, S.E., Snoek, L.B., Helmsing, N.R., Zweers, H., de Hollander, M., Soto, R.L., Bouffaud, M.L., Buée, M., Dimmers, W., Duyts, H., Geisen, S., Girlanda, M., Griffiths, R.I., Jørgensen, H.B., Jensen, J., Plassart, P., Redecker, D., Schmelz, R.M., Schmidt, O., Thomson, B.C., Tisserant, E., Uroz, S., Winding, A., Bailey, M.J., Bonkowski, M., Faber, J.H., Martin, F., Lemanceau, P., de Boer, W., van Veen, J.A., van der Putten, W.H., 2017. Soil networks become more connected and take up more carbon as nature restoration progresses. Nature Communications 8, 14349.

Nacke, H., Goldmann, K., Schöning, I., Pfeiffer, B., Kaiser, K., CastilloVillamizar, G.A., Schrumpf, M., Buscot, F., Daniel, R., Wubet, T., 2016. Fine spatial scale variation of soil microbial communities under European Beech and Norway Spruce. Frontiers in Microbiology 7, 2067.

Nemergut, D.R., Schmidt, S.K., Fukami, T., O’Neill, S.P., Bilinski, T.M., Stanish, L.F., Knelman, J.E., Darcy, J.L., Lynch, R.C., Wickey, P., Ferrenberg, S., 2013. Patterns and processes of microbial community assembly. Microbiology and Molecular Biology Reviews 77, 342-356.

Oksanen, J.Blanchet, F. G.Kindt, R.Legendre, P.Minchin, P. R.O'hara, R. B.Simpson, G. L.Solymos, P.Stevens, M. H. H.and Wagner, H.. 2013. Package 'vegan'. Community ecology package, version 2 , 1-295.

Ovaskainen, O., Tikhonov, G., Norberg, A., Guillaume Blanchet, F., Duan, L., Dunson, D., Roslin, T., Abrego, N., 2017. How to make more out of community data? A conceptual framework and its implementation as models and software. Ecology Letters 20, 561576. 
Pebesma, E., Heuvelink, G.J.R.J., 2016. Spatio-temporal interpolation using gstat. R Journal 8, 204-218.

Peng, L., Zhong, Z., Zhan-bin, L., 2004. Vertical root distribution characters of Robinia pseudoacacia on the Loess Plateau in China. Journal of Forestry Research 15, 87-92.

Pereira, A.P.A., Andrade, P.A.M., Bini, D., Durrer, A., Robin, A., Bouillet, J.P., Andreote, F.D., Cardoso, E.J.B.N., 2017. Shifts in the bacterial community composition along deep soil profiles in monospecific and mixed stands of Eucalyptus grandis and Acacia mangium. PLoS One 12, e0180371.

Prach, K., Walker, L.R., 2011. Four opportunities for studies of ecological succession. Trends in Ecology \& Evolution 26, 119 123.

Randall, K., Brennan, F., Clipson, N., Creamer, R., Griffiths, B., Storey, S., Doyle, E., 2019. Soil bacterial community structure and functional responses across a long-term mineral phosphorus $(\mathrm{Pi})$ fertilisation gradient differ in grazed and cut grasslands. Applied Soil Ecology 138, 134-143.

Rime, T., Hartmann, M., Brunner, I., Widmer, F., Zeyer, J., Frey, B. 2015. Vertical distribution of the soil microbiota along a successional gradient in a glacier forefield. Molecular Ecology 24, 1091 1108.

Shi, S., Peng, C., Wang, M., Zhu, Q., Yang, G., Yang, Y., Xi, T., Zhang, T., 2016. A global meta-analysis of changes in soil carbon, nitrogen, phosphorus and sulfur, and stoichiometric shifts after forestation. Plant and Soil 407, 323-340.

Shi, Y., Li, Y., Xiang, X., Sun, R., Yang, T., He, D., Zhang, K., Ni, Y., Zhu, Y.G., Adams, J.M., Chu, H., 2018. Spatial scale affects the relative role of stochasticity versus determinism in soil bacterial communities in wheat fields across the North China Plain. Microbiome 6, 27.

Stegen, J.C., Lin, X., Fredrickson, J.K., Chen, X., Kennedy, D.W., Murray, C.J., Rockhold, M.L., Konopka, A., 2013. Quantifying community assembly processes and identifying features that impose them. ISME Journal 7, 2069-2079.

Stegen, J.C., Lin, X., Konopka, A.E., Fredrickson, J.K., 2012. Stochastic and deterministic assembly processes in subsurface microbial communities. ISME Journal 6, 1653-1664.

Thom, D., Seidl, R., 2016. Natural disturbance impacts on ecosystem services and biodiversity in temperate and boreal forests. Biological Reviews of the Cambridge Philosophical Society 91, 760-781.

Tripathi, B.M., Stegen, J.C., Kim, M., Dong, K., Adams, J.M., Lee, Y.K., 2018. Soil $\mathrm{pH}$ mediates the balance between stochastic and deterministic assembly of bacteria. ISME Journal 12, 1072-1083.

Vitousek, P.M., Porder, S., Houlton, B.Z., Chadwick, O.A., 2010. Terrestrial phosphorus limitation: mechanisms, implications, and nitrogen-phosphorus interactions. Ecological Applications 20, 515.

Walker, T.W., Adams, A.F.R., 1958. Studies on soil organic matter: I. Influence of phosphorus content of parent materials on accumulations of carbon, nitrogen, sulfur, and organic phosphorus in grassland soils. Soil Science 85, 307-318.

Wang, J., Wang, Y., Li, M., Xu, L., He, N., Yan, P., Chen, C., Lu, Q., Feng, Y., Li, J., 2021. Differential response of abundant and rare bacterial subcommunities to abiotic and biotic gradients across temperate deserts. Science of the Total Environment 763, 142942.

Wu, W., Logares, R., Huang, B., Hsieh, C.H., 2017. Abundant and rare picoeukaryotic sub-communities present contrasting patterns in the epipelagic waters of marginal seas in the northwestern Pacific Ocean. Environmental Microbiology 19, 287-300.

Xue, Y., Chen, H., Yang, J.R., Liu, M., Huang, B., Yang, J., 2018. Distinct patterns and processes of abundant and rare eukaryotic plankton communities following a reservoir cyanobacterial bloom. ISME Journal 12, 2263-2277.

Zhang, C., Liu, G., Xue, S., Wang, G., 2016. Soil bacterial community dynamics reflect changes in plant community and soil properties during the secondary succession of abandoned farmland in the Loess Plateau. Soil Biology \& Biochemistry 97, 40-49.

Zhou, J., Deng, Y., Zhang, P., Xue, K., Liang, Y., Van Nostrand, J.D., Yang, Y., He, Z., Wu, L., Stahl, D.A., Hazen, T.C., Tiedje, J.M., Arkin, A.P., 2014. Stochasticity, succession, and environmental perturbations in a fluidic ecosystem. Proceedings of the National Academy of Sciences of the United States of America 111, E836E845.

Zhou, J., Ning, D., 2017. Stochastic Community Assembly: Does It Matter in Microbial Ecology? Microbiology and Molecular Biology Reviews 81, e00002-e00017. 